\title{
BROOKHEVEN
}

NATIONAL LABORATORY

BNL-101335-2013-CP

\section{A fast, high voltage, high frequency modulator at BNL}

\author{
Y. Tan, J.-L. Mi, J. Ritter, J. Sandberg, W. Zhang
}

Presented at IEEE Pulsed Power \& Plasma Science Conference (PPPS 2013)

San Francisco, $C A$

June 16-21, 2013

\section{Collider-Accelerator Department Brookhaven National Laboratory}

\section{U.S. Department of Energy DOE Office of Science}

\footnotetext{
Notice: This manuscript has been authored by employees of Brookhaven Science Associates, LLC under Contract No. DE-AC02-98CH10886 with the U.S. Department of Energy. The publisher by accepting the manuscript for publication acknowledges that the United States Government retains a non-exclusive, paid-up, irrevocable, world-wide license to publish or reproduce the published form of this manuscript, or allow others to do so, for United States Government purposes.

This preprint is intended for publication in a journal or proceedings. Since changes may be made before publication, it may not be cited or reproduced without the author's permission.
} 


\section{DISCLAIMER}

This report was prepared as an account of work sponsored by an agency of the United States Government. Neither the United States Government nor any agency thereof, nor any of their employees, nor any of their contractors, subcontractors, or their employees, makes any warranty, express or implied, or assumes any legal liability or responsibility for the accuracy, completeness, or any third party's use or the results of such use of any information, apparatus, product, or process disclosed, or represents that its use would not infringe privately owned rights. Reference herein to any specific commercial product, process, or service by trade name, trademark, manufacturer, or otherwise, does not necessarily constitute or imply its endorsement, recommendation, or favoring by the United States Government or any agency thereof or its contractors or subcontractors. The views and opinions of authors expressed herein do not necessarily state or reflect those of the United States Government or any agency thereof. 


\title{
A FAST, HIGH VOLTAGE, HIGH FREQUENCY MODULATOR AT BNL ${ }^{*}$
}

\author{
Y. Tan ${ }^{\xi}$, J.-L. Mi, J. Ritter, J. Sandberg, W. Zhang \\ Collider Accelerator Department, Brookhaven National Laboratory \\ Upton, NY 11973-5000, USA
}

\section{Abstract}

A high voltage modulator has been built and tested at Brookhaven National Laboratory. Its function is to drive the gun anode of the RHIC Electron Lens(e-lens). It is capable of outputting a square wave of $10 \mathrm{kV}$ and a continuous rep rate of $80 \mathrm{kHz}$. The pulse width is continuously adjustable from 500ns to DC. The rise time and the fall time (10\%-90\%) are under 50ns.

\section{I.INTRODUCTION}

Two counter-rotating particle beams consisting of polarized protons are circulated in the Relativistic Heavy Ion Collider (RHIC) at near light speed. To compensate the head-on beam-beam interactions, two e-lenses are being installed in the RHIC 10 o'clock intersection region.

The electron gun produces electron beams and the electron beam current is controlled by the anode modulator. The modulator is required to work in four modes, as shown in Table 1.

Table 1. Anode Modulator Modes

\begin{tabular}{|l|c|c|c|c|}
\hline Modes & DC & Parasitic & Setup & Diagnostic \\
\hline On & $10 \mathrm{~ms}$ & $500 \sim 1000$ & $500 \sim 1000$ & Variable \\
Time & & $n \mathrm{~ns}$ & $\mathrm{~ns}$ & $500 \mathrm{~ns}-\mathrm{DC}$ \\
\hline Off & $500 \sim 1000$ & $11.7-$ & $10 \mathrm{~ms}$ & Variable \\
Time & $\mathrm{ns}$ & $12.2 \mathrm{us}$ & & \\
\hline Freq. & $<=100 \mathrm{~Hz}$ & $78.8 \mathrm{kHz}$ & $<=100 \mathrm{~Hz}$ & $<=100 \mathrm{~Hz}$ \\
\hline
\end{tabular}

The maximum output voltage is $15 \mathrm{kV}$. We are presently using $10 \mathrm{kV}$.

The rising or falling edges must occur exactly in a space between two adjacent polarized proton bunches without impacting them, and must also couple with the BPM pick-ups to provide a robust signal for processing. A leading and trailing edge rise and fall time of under 50ns is required.

In the parasitic mode, the modulator is required to pulse once for every revolution of the particle beams in the RHIC rings. This translates to $12.7 \mathrm{us}$, or $78.8 \mathrm{kHz}$ in terms of frequency. We are using $80 \mathrm{kHz}$.

\section{II.DESIGN}

A push-pull circuit, as seen in Figure 1, is suitable to produce all of the required four modes of operation. Uc is the cathode bias voltage that floats the modulator to maximum $-10 \mathrm{kV}$. Anode voltage U1 (with respect to Uc) extracts electron beams out of the electron gun. Anode bias voltage $\mathrm{U} 2$ (with respect to $\mathrm{Uc}$ ) inhibits the electrons from being extracted. $\mathrm{U} 2$ is adjustable from $-1 \mathrm{kV}$ to $0 \mathrm{~V}$, but is normally set to $-500 \mathrm{~V}$.

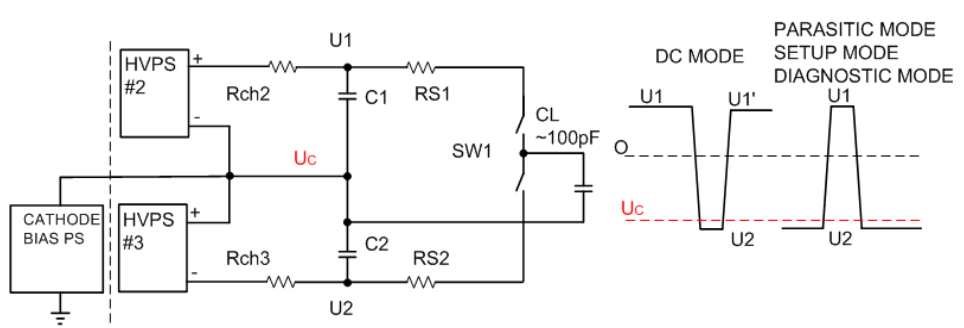

Figure 1. Simplified modulator schematic

The push-pull switch SW1 is the key component needed to achieve both the required quick rise time and fall time, and the quick pulse width variation at such high voltage. A stacked MOSFET switch (HTS301-03-GSM from Behlke) has been selected to accomplish this. Direct Liquid Cooling (DLC) is required for high frequency high power operation.

RS1 and RS2 are used for damping and for shorting protection. They share power dissipation with the switch and are liquid cooled as well.

CL, the capacitance between the anode and the cathode of the gun, is estimated to be $100 \mathrm{pF}$. Normally $\mathrm{C} 1$ would be at least 10 times that of CL in order to achieve the shortest transition times, but for operation in the DC mode, due to the energy charge to the load, the recovery voltage U1' is less than the DC level U1. The greater the capacitance of $\mathrm{C} 1$, the less the voltage difference. During the modulator development phase, arcing occurred in the

\footnotetext{
* Work supported by the Brookhaven Science Associates, LLC under contract No. DE-AC02-98CH10886 with the U.S. Department of Energy

$\xi$ email: yugang@bnl.gov
} 
electron gun. This arcing resulted in the failure of two Behlke switches in the modulator prototype. It was determined that the energy stored in $\mathrm{C} 1$ was too great for the Behlke switch to handle under those conditions. Therefore, to preserve the integrity of the expensive Behlke switch, a $500 \mathrm{pF}$ value was selected for $\mathrm{C} 1$. To facilitate the voltage drop, a charge circuit is added, as seen in Figure 2.

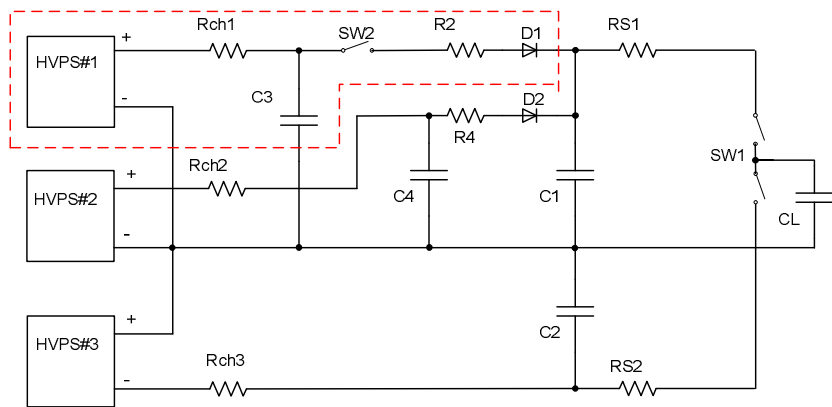

Figure 2. Upgraded modulator schematic

Figure 2 shows that HVPS\#1 and SW2 have been added to the original modulator schematic. By controlling the on time of switch SW2, we gain more control of the output voltage wave shape.

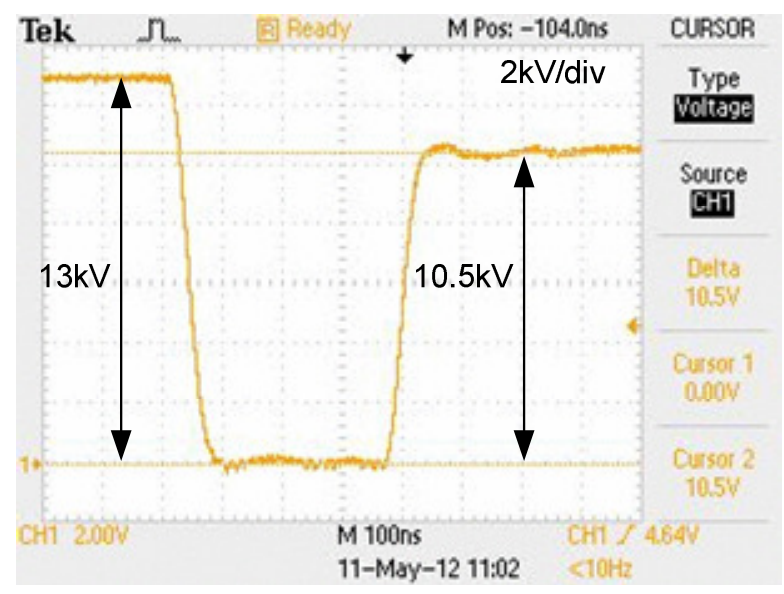

(a) Before the upgrade

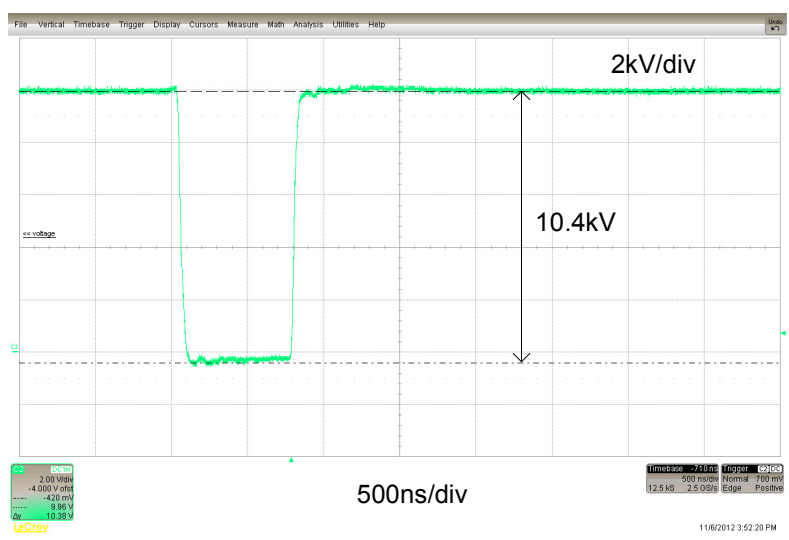

(b) After the upgrade

Figure 3. Modulator output voltage waveforms
The comparisons before and after this equipment upgrade are shown in Figure 3. As seen in (a), the recovery voltage was much lower than the charge voltage; while in (b), the recovery voltage was tuned to match the charge voltage.

The modulator picture is seen in Figure 4.

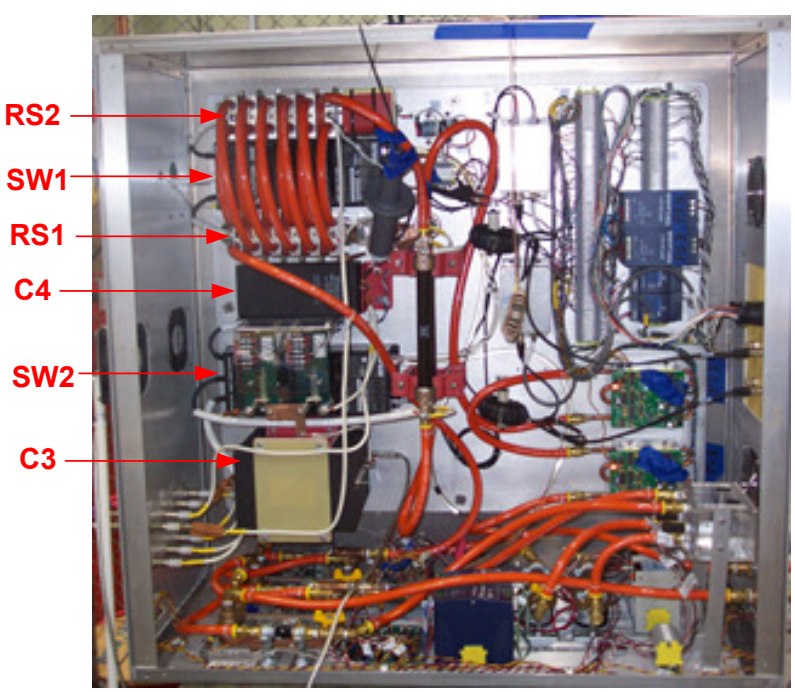

Figure 4. e-lens anode modulator

Switch SW1 dissipate the majority of the power, so it must be liquid cooled. Galden HT-135 was first used but it caused the pump and the flow sensors to fail due to the accumulating high voltage static charge. Switching to 3COM's fluorinert FC-40 proved to be effective.

There are two enclosed cooling loops. There is a pump and a heat exchanger in each loop. Loop \#1 includes the main switch SW1; Loop \#2 includes the charging switch SW2, charging resistor R2, discharge resistor RS1 and RS2, and auxiliary power supply heat sinks for SW1 and SW2. A large pump (Laing E10) is used in Loop \#1 and Loop \#2's pump is a Laing D5. Both Laing E10 and D5 are magnetically coupled so there is no shaft seal to leak. The heat is taken out by cooling water flowing through the heat exchangers.

Two Allen-Bradley SLC551 PLCs are incorporated to control the modulator. One PLC is at the floated cathode level, and the other is at ground level. They communicate with each other via Ethernet.

One PanelView serves as the human/machine interface for the local controls. Remote control is accomplished via three Power Supply Interface (PSI) units.

The control timing which is synchronized with the RHIC polarized proton bunches is transferred to the modulator control racks via fiber optic cables.

The modulator plays a very important role in the e-lens Machine Protection System (MPS). It reacts to the commands from and provides readbacks to the MPS. 


\section{III.TEST RESULTS}

The modulator was tested on the electron gun in a test stand for all four modes of operation. The modulator output voltage waveform is shown in Figure 5.

By changing the polarity of the trigger to SW1, the modulator can easily switched between the DC mode and other modes. However, for the DC mode, HVPS\#1 and HVPS\#2 voltages, SW1 and SW2 triggers need to be tuned properly in order to have a perfect negative pulse.

Figure 5 shows the anode modulator positive pulsed output voltage. The inverted pulsed output voltage is shown in Figure 3 (b).

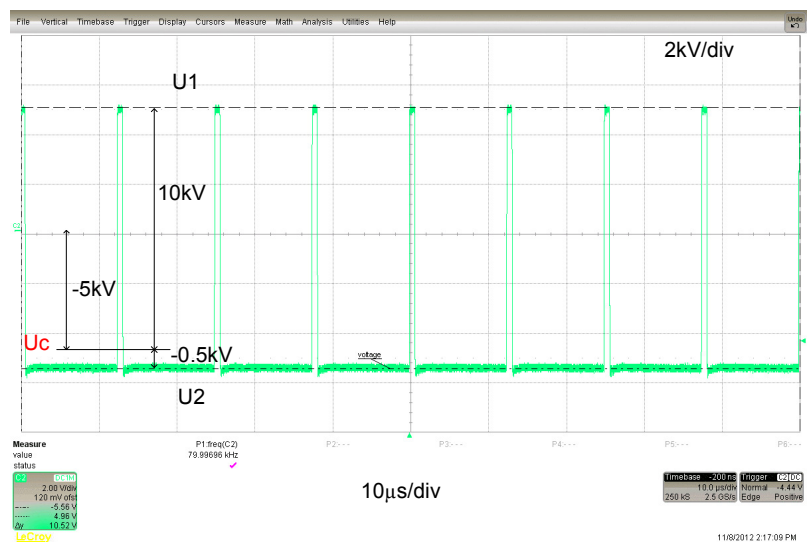

Figure 5. Modulator output voltage

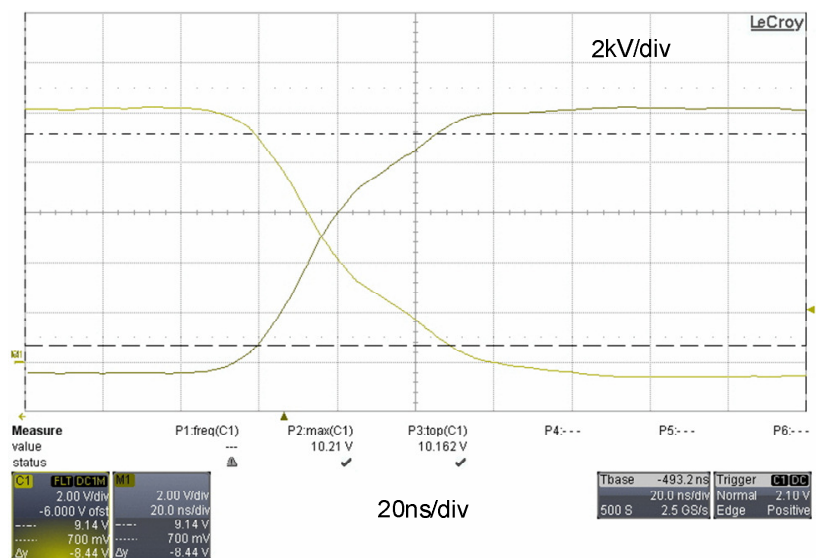

Figure 6. Modulator output voltage rise and fall time

Both the rise time and the fall time (10\%-90\%) are just under 50ns, as seen in Figure 6. The flat top flatness is $3 \%$.

The modulator was tested for heat buildup at $80 \mathrm{kHz}$ and $10 \mathrm{kV}$. The cooling fluid temperature was monitored closely in both component cooling loops as well as the cooling water temperature. The coolant temperature in both of the loops peaked at $<40^{\circ} \mathrm{C}$. This is well below the Behlke switch manufacturer's maximum temperature specification of $55^{\circ} \mathrm{C}$.
At $80 \mathrm{kHz}$, the pulse to pulse stability is better than $0.3 \%$ after a 30 -minute warm up. The rise time jitter is less than $1 \mathrm{~ns}$ and the fall time jitter is about $2 \mathrm{~ns}$.

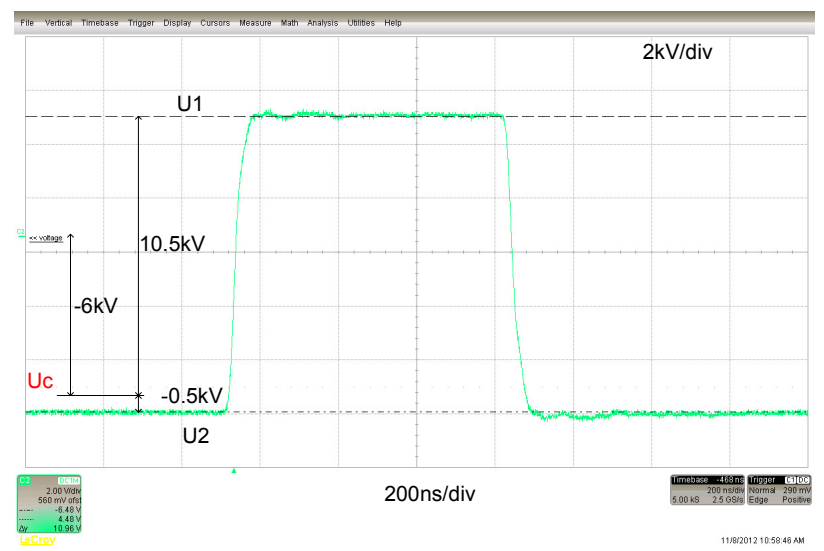

Figure 7. Modulator output voltage at $10 \mathrm{kV}$ and $80 \mathrm{kHz}$

\section{IV.SUMMARY}

This document represents the culmination of months of labor by physicists, engineers, draft people, and technicians of many varied disciplines at BNL. It describes a liquid cooled, small sized modulator capable of producing fast, high voltage, high frequency pulse with excellent rise and fall time and accuracy.

\section{V.REFERENCES}

[1] X. Gu, et al, "The e-lens test bench for RHIC beambeam compensation," in Proc. of IPAC2012, p.2720.

[2] Behlke technical datasheet for HTS301-03-GSM, available: http://www.behlke.com/pdf/301-03-gsm.pdf

\section{ACKNOWLEDGEMENT}

The author appreciates the technical supports of John Addessi, Wisman Dartiguenave, Mike Hamilton, Ken Hartmann, Steve Perlstein, Laura Taddonio and Ron Zapasek. Special thanks to Steve Perlstein for editing this document. 